\title{
A Final Word on Train Wrecks
}

\author{
Jeffrey W. Sherman \\ University of California, Davis
}

\author{
Andrew M. Rivers \\ University of British Columbia
}

\begin{abstract}
We identify the main themes raised in the commentaries and respond. To summarize: Yes, there were problems with social priming (and most other psychological) research; yes, the definition of social priming matters; no, cherry-picking specific studies to replicate does not amount to a systematic examination of the relevant research; yes, within-subjects social priming studies are robust; yes, it is wrong to conflate research reproducibility and misconduct; and, yes, it was personal.
\end{abstract}

We would like to thank the commenters who contributed their thoughts and critiques of the target article (Sherman \& Rivers, this issue). We were heartened by many of the comments, amused by some, and disappointed by others. All agreed that the distinction between within- and between-subjects designs was an important determinant of studies' subsequent reproducibility. Beyond that, whereas social psychologist responders largely agreed with our views, the critics of social priming were largely unmoved.1 As such, much of our commentary will focus on those responses. Here, we review the main themes that appeared in the commentaries and respond.

\section{Did We Understate the Problem?}

First, we respond to the concern raised by Wagenmakers (this issue) and Harris et al. (this issue) that we are sugarcoating the extent of the problems with social priming research. Counter to their claims, we wrote very clearly and explicitly in a section titled "What We are not Saying" that we do not attribute replication failures solely or primarily to a lack of power. We simply do not know the cause in most cases. We also hasten to add that the extent of the problem in terms of published Type 1 errors remains unknown in the absence of systematic work on the question (Albarracin \& Dai, this issue; Bargh, this issue; Strack \& Schwarz, this issue). The purpose of our article was not to describe the many problems confronting psychological science, which we do not deny, which existed in many domains of psychology, and which have been documented extensively. There has hardly been a lack of accounting on this front. At this point, in addition to problems with power, issues of publication bias and questionable research practices (some that were well understood at the time and some that were not) are well known. As Wagenmakers and Ferguson/Cone (this issue) describe, empirical psychology has made great strides in addressing many of these issues.

We agree with Ferguson/Cone and Harris et al. that lack of theoretical development has been a significant challenge in accounting for the results from the between-subjects social priming designs that attracted so much attention. The lack of good theory to explain some results certainly has contributed to the perception that those effects are exotic and inexplicable. At the same time, since the original publication of the archetypal social priming studies, a good deal of theoretical development has occurred (e.g., Albarracin, 2020; Loersch \& Payne, 2011; Schröder \& Thagard, 2013; Weingarten et al., 2016; Wheeler, DeMarree, \& Petty, 2007). Critics of social priming have generally paid scant attention to this work or how it may account for social priming phenomena (Lee, this issue). To be sure, as we suggest in our target article, there remains much work to be done. We described how building and validating formal mathematical models can be used to develop theories and test cognitive mechanisms implicated in priming effects. Albarracin/Dai show how a systematic examination of priming effects can help to identify the key moderators and mechanisms that produce those effects. Whether critics will attend to such efforts is an open question (Lee, this issue). 
We agree with Harris et al., Nosek, and Wagenmakers that the field of social psychology could have done a better job policing the field. This, of course, is much easier to say in retrospect and is true across many domains of psychological science. The publication norms were simply very different at the time. By the standards of the day, social priming studies were sufficiently powered and met the criteria for strong research. As well, there was little incentive at the time to attempt to replicate these studies, even among researchers skeptical of the findings. Failures to replicate had no publication home and could not be reported on social media as an alternative. In the end, the failed replications of 'social priming' effects were instrumental in challenging these norms and improving the practice of scientific psychology. Non-social psychologist "outsiders" played a crucial role in these efforts.

For related reasons, we do not view the publication of Bem's (2011) paper on ESP to have been an egregious error. To the contrary, given the publication standards at the time, there was no basis for rejecting the paper beyond a subjective sense of disbelief, which we hope all agree is not an appropriate basis for rejection. The publication of that work was a watershed moment in the movement to improve scientific practices. If that work exceeded our standards, perhaps we were doing something wrong. Had the work been buried on grounds of implausibility, we would have missed an opportunity to evaluate the normative scientific practices that led to its publication.

Finally, we decline to address Harris et al.'s views on the relative merits of direct versus conceptual replications. The opinion that conceptual replications are superior to direct replications for scientific progress is the position of the senior author of this paper alone. The reasons for this view are detailed elsewhere (Crandall \& Sherman, 2016), and nothing in Harris et al.'s commentary has changed that view. Obviously, direct replications were critical in identifying some of the problematic practices across psychological science. At the same time, it remains the opinion of the senior author that that is not the best way to build an understanding of social priming (or any other psychological phenomenon).

\section{Definitional Issues/What Counts?}

A good deal of our target article focused on definitional questions surrounding social priming. We concluded that the term social priming had no real meaning and that the research that has been identified as social priming represents a very limited subset of work that might be characterized as social priming and is not particularly social in nature. The social psychologists (Bargh; Ferguson/Cone; Strack/Schwarz; Albarracin/Dai; Lee; Nosek, all this issue) largely agreed with this assessment. Bargh, Ferguson/Cone, and Strack/Schwarz offered the important and, in our view, true point that vast swaths of research across all fields of psychology can be fairly characterized as priming. As a general rule, behavior is affected by accessible cognitive content. We are in full agreement with Lee that people do not judge what is and isn't social priming according to logical criteria. Still, we think they should. We appreciated Nosek's identification of two distinct clusters of social psychological work relying on priming techniques. That was certainly the senior author of the response's experience at the time, and is largely reflected in the use of within versus between subject designs in the two clusters.

In contrast to the social psychologist responses, Wagenmakers doesn't see the point of clearly defining the construct at the heart of all the controversy, questioning why we should care what it's called. It is difficult to take this response seriously. Presumably, the critiques were and are targeted at particular kinds of research that are deemed flawed and unreliable. Identifying the specific factors that make that research problematic seems like an important goal if one wishes to accurately diagnose the problems and effective solutions, as Albarracin/Dai discuss in depth. Both Wagenmakers and Harris et al. attempt to constrain the discussion to the subset of studies that have proven difficult to replicate. What is social priming? It's this set of studies that we can't replicate. This answer is not satisfying as a coherent diagnosis of the problem and incapable of explaining why some priming effects are replicable and others are not. The senior author of this piece was a participant in the email discussion list described by Harris et al., who recount that repeated requests for replicable social priming effects went unanswered. In fact, 
over and over again, within-subject priming effects in social psychology with social stimuli and social implications, such as those we discuss in our target article (e.g., Weapons Identification Task), were offered as examples. Over and over again, they were rejected as not being true social priming, a tour de force of the No True Scotsman fallacy (with thanks to Chris Crandall). In the end, despite our efforts then and now to describe robust social priming, the critics stand firm in their conviction that failed replication is the defining feature of research that may be considered social priming and worthy of discussion.

In their response to our target article, Harris et al. express skepticism that the within-subject social priming effects demonstrated in our article are themselves robust. They write that it is "awkward" that we cite original individual papers and not large scale pre-registered replications of those effects. We do the same for the Stroop task and semantic priming, apparently not an issue. The priming effects we describe (e.g., IAT; evaluative priming; WIT; SMT) have been widely replicated (in the thousands for IAT and evaluative priming), including the findings originating in our lab (i.e., Reichardt, Rivers, Reichardt, \& Sherman, 2020), and many times with pre-registered analysis plans (e.g., Rees, Rivers, \& Sherman, 2019). This is not the type of exotic work that receives headline coverage, nor does it appear to even receive consideration by those who are altogether skeptical of social priming effects. We (again) recommend that Harris et al. try one of these paradigms in their quest to find a replicable social priming effect.

\section{Systematic Examination?}

However, even if we restrict our analysis to between-subjects social priming studies, the focus is on a rather narrow subset of the research. Harris et al. describe their foray into the world of social priming as being driven by a desire to replicate "the most (to us) surprising and fascinating priming results." They scold us for not focusing sufficiently on those priming effects that "seem to have fascinated so many people." Both Wagenmakers and Harris et al. trumpet the efforts of the Open Science Collaborations as proof of the widespread nature of the problem. Harris et al. note the inclusion of not one but two(!) social priming studies in Many Labs 1 (Klein et al., 2014). Whatever their other virtues, these efforts do not represent a systematic analysis of the research or even a representative sample. Beyond notoriety, the basis for selection has included features such as ease of reproducing materials, ease of online implementation, and ease of insertion into a session including many other studies. Our point is not to assert that a broader sampling would show many of the between-subject effects to be robust. We do not know. The point is to note, once again, the lack of interest in a systematic examination of social priming. This is in stark contrast to systematic reviews and meta-analyses of social priming research (Chen, Latham, Piccolo, \& Itzchakov, 2020; Dai et al., 2020; Shariff, Willard, Andersen, \& Norenzayan, 2016; Weingarten et al., 2016).

Aside from the selective nature of replication efforts, they have not always met standards of sound research. Strack/Schwarz and Albarracin/Dai note that valid priming research requires the sometimes difficult work of confirming that the primes activate the content that they are meant to. This standard has not always been met in replication attempts (Ramscar, 2016; Ramscar, Shaoul, \& Bayen, 2015). As well, claims of non-replicability have sometimes been based on statistical practices that deviate from best practices (Lee \& Schwarz, 2020). Moreover, as noted by Lee, motivated reasoning about research outcomes is not restricted to authors of new research results (Wagenmakers), and is readily found among claims of non-replication. Altogether, the critics of social priming have largely expressed little interest in identifying the factors that differentiate social priming studies that are and are not easily replicated. This belies straight-faced and selfrighteous assurances of a desire only to improve science, and is indicative of a more base Gotcha! motive.

\section{Reproducibility Versus Misconduct}

Here, we revisit our discussion of the appropriateness and consequences of the framing of failed replications in social priming. In our target article, we wrote about the damage done by the conflation of reproducibility issues and scientific misconduct. Both Wagenmakers and 
Harris et al. dismiss this commentary and assert that the damage done was a natural and fair outcome of replication failure. $\mathrm{We}$ are disappointed but not surprised in this response. Both continue to feel justified in concluding that failed replications in social priming reflect, in part, the use of questionable research practices or other misconduct without supporting evidence. A main theme of our target article was that the cause of replication failures is difficult to assess, particularly when original studies and replications are under-powered. As well, we argue that suggestions of misconduct should be avoided unless and until there is clear evidence. We maintain that position and urge researchers to withhold judgment in the absence of such evidence. It is simply inappropriate to cast such aspersions and it is corrosive (see Albarracin \& Dai; Lee, this issue).

Both Wagenmakers and Harris et al. also continue to discuss the fraud committed by Diederik Stapel as part and parcel of the discussion of reproducibility. We continue to object strenuously to this practice. Social psychology is called to task for not having discovered Stapel's fraud sooner and that Stapel's students were the ones to report it. We would note here that the vast majority of research fraud goes undetected, that it often continues for years before it is detected, and that students and postdoctoral fellows working in a scientist's lab are often the ones who detect it (Fang, Steen, \& Casadevall, 2012; Gross, 2016). This appears to be true across all domains of science.

Much of our discussion of the conflation of reproducibility and misconduct centered on the actions taken by Daniel Kahneman, who is defended strenuously by both Wagenmakers and Harris et al. We agree that Kahneman likely had good motives. At the same time, he was certainly not blameless and, at best, naïve about the consequences of his language. We quoted the parts of Kahneman's letter in which he questioned the integrity of social priming researchers and called the work suspicious, which was inappropriate and which did cause significant damage (Lee, this issue). Harris et al.'s claim that he didn't know about the power issue is incorrect. He had been made aware of that issue. In short, we do not feel that we have treated Kahneman unfairly.

\section{The Social Context of Social Priming Criticism}

Finally, Wagenmakers challenges our view that personal animosity played a role in the nature of the critiques of social priming. People who were there disagree, whether they felt targeted by the critiques (Albarracin \& Dai; Lee, this issue), were sympathetic to the critiques (e.g., Funder, 2020), or were neutral observers (Dominus, 2017). Anybody who was there knows, and to suggest otherwise beggars belief. So, here, Wagenmakers graduates from mere trolling into full blown gaslighting. We do thank him for providing an excuse to revisit The Naked Gun, and are content to liken Kahneman to Frank Dreben in the context of social priming. But, we think him too modest. If Kahneman deserves the role of Frank Dreben, so too does Wagenmakers, who also was a prominent public critic who conflated (and continues to conflate) questions of reproducibility and misconduct. However, we also think him too generous to Dreben, who continually destroys things (and people) through pure bumbling idiocy. Accordingly, Wagenmakers leaves out one critical component of the scene in question. After Vincent Ludwig falls to his death, the Worried Lady stares at Dreben in disbelief at what a blundering fool he is.

\section{References}

Albarracin, D.. (2020). Action and inaction in a social world: Predicting and changing attitudes and behaviors. Cambridge University Press.

Albarracin, D., \& Dai, W. (this issue). Priming effects on behavior and priming behavioral concepts: A commentary on Sherman and Rivers (2021). Psychological Inquiry.

Bargh, J. A. (this issue). All aboard! 'Social' and nonsocial priming are the same thing. Psychological Inquiry.

Bem, D. J. (2011). Feeling the future: Experimental evidence for anomalous retroactive influences on cognition and affect. Journal of Personality and Social Psychology, 100, 407-425.

Chen, X., Latham, G., Piccolo, R., \& Itzchakov, G. (2020). An enumerative review and a meta-analysis of primed goal effects on organizational behavior. Applied Psychology.

Crandall, C. S., \& Sherman, J. W. (2016). On the scientific superiority of conceptual replications for scientific progress. Journal of Experimental Social Psychology, 66, 93-99.

Dai, W., Yang, T., White, B. X., Palmer, R., Sanders, E., McDonald, J. ., \& Albarracin, D. (2020). Priming Behaviors vs. Ideas: A Meta-Analysis of the Effects of Behavioral and Nonbehavioral Primes on Overt 
Behavioral Outcomes [Manuscript submitted for publication], Department of Psychology, University of Illinois at Urbana Champaign.

Dominus, S. (2017, October). When the revolution came for Amy Cuddy. The New York Times Magazine.

Fang, F. C., Steen, G., \& Casadevall, A. (2012). Misconduct and retractions. Proceedings of the National Academy of Sciences, 109, 17028-17033.

Ferguson, M. J., \& Cone, J. (this issue). The role of intentionality in social* priming. Psychological Inquiry.

Funder, D. C. (2020, May 8). Thoughts on "Ego Depletion" and some related issues concerning replication. Funderstorms. Accessed at: https://funderstorms.wordpress.com/2020/05/08/thought s-on-ego-depletion-and-some-related-issues-concerningreplication/

Gross, C. (2016). Scientific misconduct. Annual Review of Psychology, 67, 693-711.

Harris, C., Rohrer, D., \& Pashler, H. (this issue). A train wreck by any other name. Psychological Inquiry.

Klein, R. A., Ratliff, K. A., Vianello, M., Adams, R. B., Bahník, S., Bernstein, M. J.,... Nosek, B. A. (2014). Investigating variation in replicability: A "many labs" replication project. Social Psychology, 45, 142-152.

Lee, S. W. S. (this issue). "Social priming" through the lens of sociology of science: Fuzzy boundary, personal experience, and broader atmosphere. Psychological Inquiry.

Lee, S. W. S., \& Schwarz, N. (2020). Grounded procedures: A proximate mechanism for the psychology of cleansing and other physical actions. Behavioral and Brain Sciences, 43, 1-78.

Loersch, C., \& Payne, B. K. (2011). The Situated Inference Model: An integrative account of the effects of primes on perception, behavior, and motivation. Perspectives on Psychological Science, 6, 234-252.

Nosek, B. A. (this issue). We are in it together. Psychological Inquiry.

Ramscar, M. (2016). Learning and the replicability of priming effects. Current Opinion in Psychology, 12, 8084.

Ramscar, M., Shaoul, C., \& Baayen, R.H. (2015). Why many priming results don't (and won't) replicate: $A$ quantitative analysis. Working paper; University of Tübingen.

Rees, H. R., Rivers, A. M., \& Sherman, J. W. (2019). Implementation intentions reduce implicit stereotype activation and application. Personality and Social Psychology Bulletin, 45, 37-53.

Reichardt, R., Rivers, A. M., Reichardt, J. \& Sherman, J. W. (2020). Further validation of measures of Target Detection and Stereotype Activation in the Stereotype Misperception Task. Frontiers in Psychology. https://doi.org/10.3389/fpsyg.2020.573985

Schröder, T., \& Thagard, P. (2014). Priming: Constraint satisfaction and interactive competition. Social Cognition, 32, 157-172.

Shariff, A. F., Willard, A. K., Andersen, T., \& Norenzayan, A. (2016). Religious priming: A meta-analysis with a focus on prosociality. Personality and Social Psychology Review, 20, 27-48.
Sherman, J. W., \& Rivers, A. M. (this issue). There's nothing social about social priming: Derailing the "Train Wreck." Psychological Inquiry.

Strack, F., \& Schwarz, N. (this issue). What's on your mind? Psychological Inquiry.

Wagenmakers, E. J. (this issue). Defiant denial is selfdefeating. Psychological Inquiry.

Weingarten, E., Chen, Q., McAdams, M., Yi, J., Hepler, J., $\&$ Albarracín, D. (2016). From primed concepts to action: A meta-analysis of the behavioral effects of incidentally presented words. Psychological Bulletin, 142, 472-497.

Wheeler, S. C., DeMarree, K. G., \& Petty, R. E. (2007). Understanding the role of the self in prime-to-behavior effects: The active-self account. Personality and Social Psychology Review, 11, 234-261. 